\title{
USE OF DIGITAL TOOLS TO TRAIN PREVENTION OF BUILDING ACCIDENTS
}

\author{
A. Soeiro \\ Universidade Porto (PORTUGAL) \\ avsoeiro@fe.up.pt
}

\begin{abstract}
Construction industry remains one of the most hazardous industries to work in, despite numerous efforts by researchers and practitioners to improve levels of Health \& Safety (H\&S) and reduce the number of accidents which occur on the construction sites. A potential method to reduce the number accidents is to educate construction workers in hazard identification and to raise their awareness of the risks they face at the construction site through the use of emerging technologies such as Virtual Reality (VR) and Augmented Reality (AR). This paper presents the first intellectual output of an Erasmus+ project titled Construction Safety with Education and Training using Immersive Reality (CSETIR), whose goal is to examine and apply such VR and AR tools to improve the levels of H\&S. Through the literature review and discussions with relevant stakeholders, most appropriate training methods were identified for the development of safety educational tools in the following project phases. VR and AR technologies have the potential to train construction workers in H\&S, especially those who have little experience in construction safety, workers with literacy limitations and workers that do not speak the local language. Visual training tools, especially immersive ones, also provide better retention of acquired knowledge and skills. An immersive reality safety education tool, therefore, has the potential to increase the levels of construction H\&S and to reduce the number of accidents at construction sites. Several tools, sixteen, have been tested and the construction of training scenarios has been initiated. The advantages and obstacles to use the tools have been identified and a comparison of indicators has been produced. A demonstration of the application for the prototype has been created allowing the testing and validation.
\end{abstract}

Keywords: Construction Accidents, Prevention, Digital Tools, BIM. 